\title{
Efficacy of orally administered salbutamol and theophylline in pre-schoolchildren with asthma
}

\author{
R C GROGGINS, W LENNEY, A D MILNER, AND G M STOKES \\ Department of Child Health, Queens Medical Centre, University of Nottingham
}

SUMMARY Oral administration of salbutamol and theophylline has been shown to be effective in relieving bronchoconstriction in asthmatic children aged between 3 and 5 years. Changes in respiratory function were monitored using a Wright's low range peak flow meter and a modification of the forced oscillation technique. A combination of both drugs in half doses was as effective as either alone. Nebulised salbutamol produced considerable further improvement in lung function.

Asthma affects up to $10 \%$ of pre-schoolchildren and is often, although inappropriately, described as recurrent wheezy bronchitis. ${ }^{1-2}$ Wheezing attacks at this age are most conveniently treated with oral medication using either $\beta$ adrenergic stimulants or $x$ anthine derivatives. It is now well established that $\beta-2$ stimulants are effective when given by inhalation down to age 18 months, ${ }^{3}$ but to our knowledge, no double-blind controlled study has been performed to assess objectively the effectiveness of orally administered drugs in the pre-schoolchild. We therefore set out to investigate the bronchodilator properties of two oral preparations, salbutamol, a $\beta-2$ stimulant, and theophylline, a xanthine derivative.

\section{Material and methods}

Subjects. 15 children, 9 girls and 6 boys, aged 2 years 11 months to 5 years 8 months (median 3 years 10 months) took part in the study. All had suffered from recurrent wheezing attacks with onset of symptoms between ages 3 months and 4 years (median 21 months).

12 children had a family history of asthma and 4 of them also suffered from eczema. 13 of the children had required admission to hospital at least once (range 1-7). Seven children had nebulisers at home and were treated with sodium cromoglycate solution and salbutamol respirator solution. One further child was treated with sodium cromoglycate using a spinhaler, and the remaining 7 with

\footnotetext{
Department of Child Health, Queen's Medical Centre R C GROGGINs, research fellow A D MILNER, reader in child health

G M STOKES, research assistant

Royal Alexandra Hospital for Sick Children, Brighton, Sussex

W LENNEY, senior registrar
}

inhaled (4) or oral (3) salbutamol. All the children had previously undergone respiratory function testing and shown at least a $15 \%$ improvement in total respiratory resistance $\left(\mathbf{R}_{\mathrm{T}}\right)$ and peak expiratory flow rate (PEFR) after inhaling $2 \mathrm{ml} 0.125 \%$ salbutamol respirator solution from a nebuliser.

Apparatus. Two systems were used to assess lung function:

Wright's low range peak flow meter. This gives reproducible results of PEFR down to age $2 \frac{1}{2}$ years. ${ }^{4}$ A modification of the forced oscillation technique. The technique is based on the principle that when a sine wave flow oscillation is applied to the respiratory system at the resonant frequency, the impedance to the oscillatory flow is due soley to the $R_{T}$, since at resonance the elastic and inertial components are of equal magnitude and opposite in sign. The apparatus has been described previously in detail. ${ }^{2}$

Procedure. The children were studied on four occasions, always at the same time of day, and usually within a period of 2 weeks. All treatment was stopped for at least 12 hours before each session. On arrival in the respiratory unit, each patient was questioned about his recent health and a clinical examination was performed. Baseline measurements of heart rate, PEFR (best of three attempts using a Wright's low range peak flow meter), and $\mathbf{R}_{\mathrm{T}}$ using the modified forced oscillation technique were recorded. After resting for 15 minutes, all investigations were repeated. Each child then received one of four oral treatments, and tests were carried out after a further $5,15,30,60,75$, and 90 mintues. Oral treatment was administered under double-blind controlled conditions and consisted of two syrups containing salbutamol, theophylline, or 
placebo as shown in the Table. The theophylline was made up in a nonalcoholic solution containing $10 \mathrm{mg} / \mathrm{ml}$, so that a $20-\mathrm{kg}$ child would receive $14 \mathrm{ml}$. The salbutamol syrup was diluted to $0 \cdot 14 \mathrm{mg} / \mathrm{ml}$, enabling identical volumes of each syrup to be used. At the end of the 90-minute period, each child inhaled salbutamol respirator solution from a commercially available nebuliser (Pari) using $1 \mathrm{ml}$ $0.5 \%$ solution diluted to $2 \mathrm{ml}$ with water. All tests were repeated 10 minutes later.

\section{Results}

The children tolerated the medication well with the exception of one child who suffered nausea after all four treatments. 11 children preferred the salbutamol/placebo rather than the theophylline/ placebo syrup. Heart rate was recorded in 11 of the children. The mean baseline reading in the treatment groups ranged from $106 \cdot 2$ to $110 \cdot 7$ beats/minute. At no time after oral treatment did the group mean exceed the baseline by more than 4 beats/minute. There was a mean rise of $13.7 \%$ in heart rate after nebulised salbutamol.

Lung function on arrival at the unit tended to be worse on the day the children received theophylline, but differences between groups did not reach statistical significance (Figs 1, 2, and 3). During the

Table Oral treatment regimens used for each child

\begin{tabular}{lll}
\hline Treatment & Syrup A & Syrup B \\
\hline 1 & Salbutamol $(0.1 \mathrm{mg} / \mathrm{kg})$ & Placebo \\
2 & Placebo & Theophylline $(7 \mathrm{mg} / \mathrm{kg})$ \\
3 & Salbutamol $(0.05 \mathrm{mg} / \mathrm{kg})$ & Theophylline $(3.5 \mathrm{mg} / \mathrm{kg})$ \\
4 & Placebo & Placebo \\
\hline
\end{tabular}

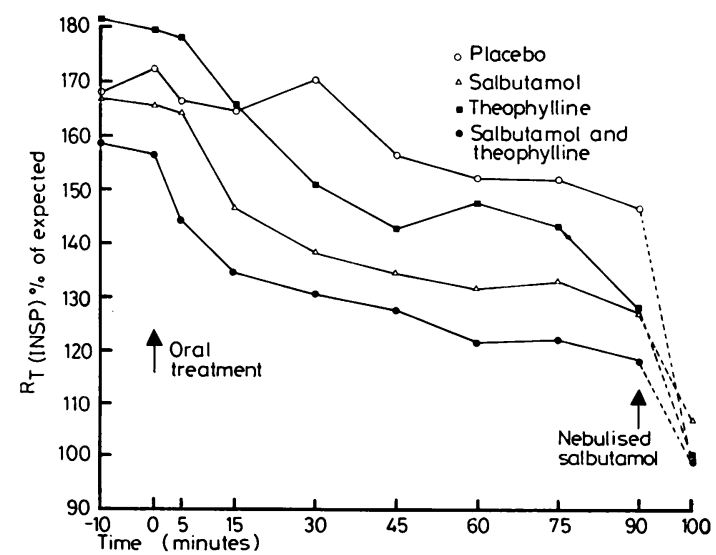

Fig. 1 Mean inspiratory $R_{\mathrm{T}}$ before and after the four oral treatments and after nebulised salbutamol. Results are expressed as a percentage of that expected for height.

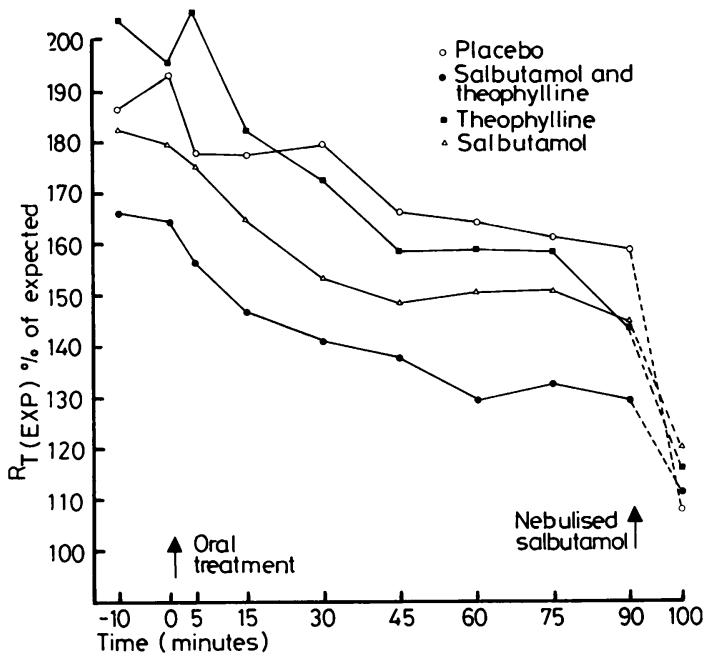

Fig. 2 Mean expiratory $R_{\mathrm{T}}$ before and after the four oral treatments and after nebulised salbutamol. Results are expressed as a percentage of the expected inspiratory resistance for height. ${ }^{7}$

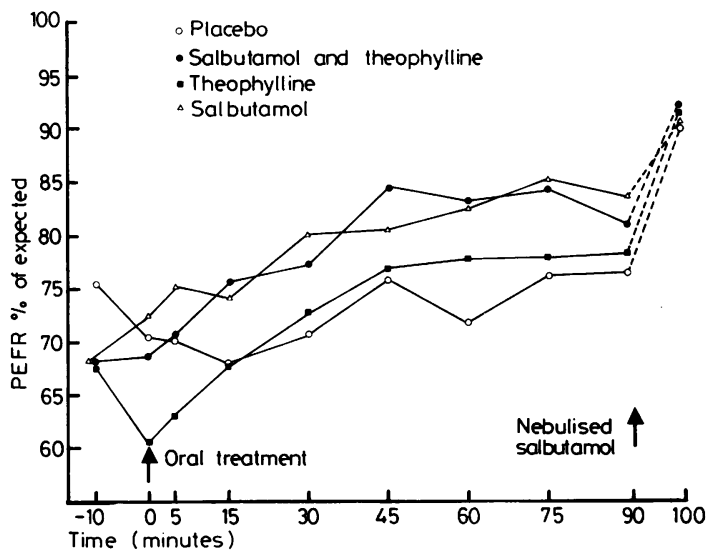

Fig. 3 Mean PEFR before and after the four oral treatments, and after nebulised salbutamol. Results expressed as a percentage of that expected for height. ${ }^{4}$

next 30 minutes lung function improved after the three active preparations, but there was little change after the placebo syrups. Lung function results tended to show further improvement during the next 60 minutes in all four groups. There was a further improvement in respiratory function after the inhalation of salbutamol so that all mean inspiratory $R_{T} s$ then fell within $8 \cdot 4 \%$ of the expected value. The expiratory $\mathbf{R}_{\mathbf{T}} \mathrm{S}$ were consistently higher than inspiratory.

All treatment groups were significantly better than 
placebo at 30 minutes $(0.05>P>0.01)$, when results were expressed as a percentage of the mean of the two pretreatment results. Subsequently, all treated groups fared better than placebo, but the differences did not reach statistical significance. Although the improvement appeared (Figs 1, 2, and 3) to be greatest after the theophylline, this finding was not apparent when the results were expressed as a percentage change from initial.

The combined treatment appeared to be as effective as either salbutamol or theophylline given in full dose alone.

\section{Discussion}

This trial shows that both oral salbutamol and theophylline are effective in relieving airways obstruction in pre-schoolchildren with asthma. Spontaneous improvement tended to take place about $\mathbf{4 5}$ minutes after placebo so that improvements with active treatment did not reach statistical significance after that time. Nevertheless, we have no doubt that oral administration of these drugs is useful in young asthmatics. Our patients had fairly severe asthma and were selected as being likely to have airways obstruction on each attendance. It may be that children with mild episodic asthma would respond more strikingly.

The improvement after inhaled salbutamol suggests that the oral drugs produced only about half the maximum available bronchodilation. It may be that higher oral doses of salbutamol would produce further improvement without causing unpleasant side effects. Previous experience ${ }^{5}$ makes it unlikely that the children could tolerate a much higher dose of theophylline.

Combined treatment in half strength doses was as effective as single drug treatment. It is likely that the full dose of salbutamol and theophylline combined will achieve better results than either alone. Previous work $^{6}$ shows that in asthmatic children aged between 6 and 10 years, continuous treatment produces better lung function and fewer symptoms than is obtained by intermittent treatment and it may be that this young group would also benefit from continuous therapy if symptoms are sufficiently troublesome to justify this.

This study further supports the use of nebulised solutions in children responding poorly to oral therapy.

We thank the children and their parents for their help with this project.

We are grateful for financial support from the Asthma Research Council, and for additional help from Glaxo-Allenbury Research Limited, and Rona Laboratories.

\section{References}

1 Williams H, McNicol K N. Prevalence, natural history, and relationship of wheezy bronchitis and asthma in children. An epidemiological study. Br Med J 1969; iv: 321-5.

2 Lenney W, Milner A D. Recurrent wheezing in the pre-school child. Arch Dis Child 1978; 53: 468-73.

3 Lenney W, Milner A D. At what age do bronchodilator drugs work? Arch Dis Child 1978; 53: 532-5.

4 Milner A D, Ingram D. Peak expiratory flow rates in children under 5 years of age. Arch Dis Child 1970; 45: 780-2.

5 Hambleton G, Weinberger M, Taylor J, et al. Comparison of cromoglycate (Cromolyn) and theophylline in controlling symptoms of chronic asthma. Lancet 1977; 1: 381-5.

6 Lenney W, Milner A D, Hillier E J. Continuous and intermittent salbutamol tablet administration in asthmatic children. Br J Dis Chest 1979; 73: 277-81.

7 Cogswell J J. Forced oscillation technique for determination of resistance to breathing in childhood. Arch Dis Child 1973; 48: 259-66.

Correspondence to Dr A D Milner, Department of Child Health, Queen's Medical Centre, Nottingham NG7 2UH.

Received 10 April 1979 